\title{
CRENÇAS E NECESSIDADES DE APRENDIZES DE JAPONÊS COMO LE (LÍNGUA ESTRANGEIRA) A RESPEITO DA HABILIDADE DA ESCRITA E MATERIAIS DIDÁTICOS
}

Yûki Mukai

Resumo: O presente trabalho investiga as crenças e necessidades de estudantes de Japonês como Língua Estrangeira (doravante JLE) em relação à habilidade da escrita e a seus materiais didáticos. O objetivo desta pesquisa, além de reconhecer essas crenças e necessidades de estudantes de JLE, é compreender as posturas atuais deles em relação ao seu estudo. Para isso, a presente pesquisa baseou-se nos conceitos de crenças apresentados por Alvarez (2007), Barcelos (2001, 2006, 2007), Conceição (2004), Kalaja (2005), Pajares (1992), McKay (2003), Kawaguchi; Yokomizo (2005) e na definição de escrita proposta por Yui (2005). Utilizou-se o método Split que mescla as abordagens qualitativa e quantitativa. Os participantes desta pesquisa-piloto foram estudantes de nível intermediário do curso de Letras-Japonês da Universidade de Brasília. Para a coleta dos dados, foram aplicados um questionário (pesquisa quantitativa) e uma entrevista (pesquisa qualitativa). Como resultado, foi revelado que, quanto às crenças sobre escrita, os participantes desta pesquisa acreditam que o ato da escrita em japonês no dia-a-dia não é tão importante se comparado com as outras habilidades, e que há uma carência de materiais para escrita e de oportunidades de escrever em japonês que aumentem sua motivação. O que se pode concluir a partir destes resultados é que, para os estudantes de JLE desenvolverem sua habilidade da escrita, são necessários materiais didáticos e oportunidades de aumentar sua motivação para que se escreva (digite) em japonês diariamente, além do desenvolvimento de materiais didáticos que incluam materiais online que possam levar a uma autonomia no aprendizado.

1. Este artigo é uma versão modificada da comunicação "Beliefs of JFL Learners on Japanese writing skills - A Case Study of JFL Learners of Istanbul Bilgi University and University of Brasilia -, apresentada no "10th Japanese Teachers' Meeting of Turkey", na Universidade Sabancı (em Istambul) em 22 e 23 de agosto de 2011.

2. Doutor em Linguística Aplicada. Professor Adjunto do Instituto de Letras da Universidade de Brasília (UnB). 
Palavras-chave: ensino-aprendizagem de língua japonesa; habilidade da escrita; crenças; necessidades; materiais didáticos.

ABSTRACT: This paper looks into the beliefs and needs of students of Japanese as a Foreign Language (henceforth JFL) regarding writing skills and teaching materials. The aim of this research is to understand JFL students' present attitude towards their studies as well as to identify their beliefs and needs. To achieve that, the concepts of beliefs presented by Alvarez (2007), Barcelos $(2001,2006,2007)$, Conceição (2004), Kalaja (2005), Pajares (1992), McKay (2003), Kawaguchi; Yokomizo (2005) and the definition of writing proposed by Yui (2005) were used. As for the methodology, the split method, which mixes both qualitative and quantitative approaches, was used as an analysis procedure. The participants in this pilot research were students of intermediate level in the Japanese Language and Literature course of the University of Brasilia. The data was collected by means of a questionnaire (quantitative research) and an interview (qualitative research). In regard to beliefs concerning writing, it was revealed that the participants in this research believe that the act of writing in Japanese daily is not so important if compared with other skills. It was also verified that there is a lack of teaching materials for writing and opportunities that motivate them to write in Japanese. It can be concluded from these results that for the JFL students to develop their writing skills it is necessary to provide them with teaching materials and opportunities to motivate them to write (type) in Japanese daily, besides developing online teaching materials which may lead them to learning autonomy.

Keywords: Japanese language teaching-learning; writing skill; beliefs; needs; teaching materials.

\section{Introdução}

O presente trabalho tem foco nas crenças e necessidades de estudantes de japonês, no concernente à habilidade da escrita ${ }^{3}$ e de materiais didáticos voltados a essa competência.

A partir da década de 1980, o método comunicativo começou a ganhar reputação e ser amplamente usado. Por conseguinte, a interlíngua e a questão emocional envolvidas na aquisição da língua por parte dos estudantes passaram a ganhar maior atenção. Esse método que coloca o aluno no centro do processo de aprendizagem (TUDOR, 1996) também exerce grande influência no desenvolvimento das pesquisas a respeito das crenças na aprendizagem de línguas estrangeiras (doravante LE).

Como Mukai (2011) aponta, por mais que um professor domine técnicas de ensino, se seu ponto de vista e o do aluno forem muito diferentes, o ensino de uma LE pode acabar fracassando. Ou seja, a pesquisa das crenças do estudante é imprescindível no ensino de línguas.

Nos Estados Unidos, a pesquisa das crenças de estudantes de Inglês como segunda língua (L2) começou a se popularizar na década de 1980. Já no Brasil, a pesquisa de crenças de estudantes de Inglês como LE teve início na década de 1990. Hoje, a pesquisa de crenças tem alcançado notável desenvolvimento mesmo na área

3. A escrita aqui mencionada também inclui a digitação. Sua definição se encontra na terceira seção deste artigo. 
de Linguística Aplicada (SILVA, 2010). No entanto, excetuando-se os estudantes de inglês, ou pelo menos no caso dos estudantes de Japonês como LE (doravante JLE) no Brasil, a pesquisa de crenças ainda resta como um tema pouco estudado.

A partir destes problemas, o presente trabalho investiga as crenças e necessidades de estudantes de ЛLE em relação à habilidade da escrita e a materiais didáticos voltados a tal competência.

O autor deste trabalho é um membro do projeto "Elaboração e uso de materiais didáticos online de japonês para a comunicação" (representante da pesquisa: Profa. Dra. Mina Kobayashi, Universidade de Waseda, em Tóquio), auxiliado subsidiado pela pesquisa científica de 2009-2013. A razão pela qual o autor, dentre as quatro habilidades da língua, foca na escrita é por estar no grupo referente à escrita dentro do projeto mencionado acima. Como pesquisa-piloto sobre a escrita de estudantes de JLE, o autor realizou uma pesquisa com questionário (pesquisa quantitativa) e com entrevista (pesquisa qualitativa) aplicados aos alunos de japonês do nível intermediário do Curso de Letras-Japonês da Universidade de Brasília, instituição na qual é professor.

O objetivo desta pesquisa, além de reconhecer as crenças e necessidades de estudantes de JLE a respeito da escrita e de seus materiais didáticos, é por meio destes compreender as posturas atuais deles em relação ao seu estudo. Diz-se comumente que, no ensino-aprendizagem de línguas estrangeiras, há diferenças entre o modo de pensar do professor e o do estudante. No entanto, a diferença não é algo ruim, sendo importante que o professor reconheça sua existência em primeiro lugar. A partir do momento em que se reconhecem as diferenças, as crenças e necessidades do aluno se tornam claras. $\mathrm{E}$ isso se liga ao desenvolvimento de materiais didáticos para a escrita, o que também é um objetivo final desta pesquisa.

\section{Conceito de Crenças}

As crenças referentes ao ensino de LE, em um sentido amplo, são "conceitos e preconceitos relativos ao estudo de determinada língua estrangeira" (HORWITZ, 1987) ou "algo como pensamentos, palavras e crenças que as pessoas têm sobre esse estudo" (THE JAPAN FOUNDATION [Org.], 2006).

Ainda quando o estudo sobre crenças dos aprendizes se popularizou, as crenças eram consideradas meramente como ideias preexistentes, preconcepções (Horwitz, 1987) ou como sinônimo de conhecimento metacognitivo (WENDEN, 1999). Ou seja, as crenças eram concebidas como estáveis e imutáveis.

Hoje, tanto para Barcelos (2006) quanto para Kalaja (1995), as crenças não devem ser consideradas apenas como processo cognitivo, mas sim como processo interativo e socialmente construído, ou seja, elas são vistas como não-estáveis, sociais, dinâmicas, contextuais e paradoxais, uma vez que nascem das experiências atuais e 
passadas, sendo formadas com base na interação e na adaptação junto ao ambiente em que estamos inseridos (BARCELOS, 2006, 2007).

Barcelos (2001) enfatiza que, ao se estudar as crenças dos estudantes e dos próprios professores, suas experiências até o presente e seu contexto social são importantes. Conceição (2004) também menciona que as experiências passadas de estudantes e professores influenciam o seu comportamento atual. Ou seja, pode-se dizer que as crenças são formadas tendo como base as experiências tanto passadas quanto presentes de aprendizagem e de ensino, e também por meio da interação com o ambiente e terceiros. Ainda, os pesquisadores (ALVAREZ, 2007; BARCELOS, 2001, 2006, 2007; CONCEIÇÃO, 2004; KALAJA, 2005; PAJARES, 1992) afirmam que tanto para o professor quanto para o estudante, as experiências passadas/ presentes de ensino e aprendizagem, assim como o contexto social participam em sua formação de crenças, se tornando a base do seu comportamento atual.

As crenças quanto ao ensino de LE podem ser divididas, principalmente, em: (1) crenças dos estudantes; (2) crenças dos professores; e (3) crenças dos coordenadores e diretores escolares (SILVA, 2010). Entretanto, neste trabalho serão focadas apenas as crenças dos estudantes.

Por exemplo, temos a crença de que conversação é o mais importante em uma aula de LE, que é uma crença de estudantes a respeito da metodologia. Outro exemplo é a crença de estudantes de que materiais que usam textos e diálogos direcionados a nativos (como artigos de jornais ou filmes na $L E$ ) são melhores, uma crença relativa a materiais didáticos.

O mais importante para o professor é reconhecer suas próprias crenças e as crenças dos estudantes. Ele sempre deve, primeiramente, conseguir definir com clareza o que ele considera ser bom, reconhecer o porquê de achar que isso é bom (McKAY, 2003, p.2) e refletir se isso realmente é bom para os estudantes com quem está trabalhando (KAWAGUCHI; YOKOMIZU, 2005, p.8).

Neste estudo, conforme Barcelos (2006, 2007), concebemos crenças como interativas e socialmente co-construídas baseadas nas nossas experiências anteriores e presentes, sendo ininterruptamente configuradas com base na ação, interação e adaptação dos indivíduos a seus contextos específicos.

\section{Definição de escrita}

Diferentemente das línguas ocidentais, o ato da escrita em japonês requer as duas habilidades a seguir: (1) a habilidade de transcrever (a mão ou por digitação) utilizando-se os três sistemas gráficos da língua japonesa: hiragana (fonograma próprio do mesmo idioma), katakana (fonograma usado para palavras de origem estrangeira) e kanji (ideogramas chineses); (2) a habilidade de redigir levando em 
consideração o contexto, tais como a comunicação, o leitor e os meios envolvidos (YUI, 2005). Assim, convém lembrar que, neste trabalho, a escrita em japonês compreende dois níveis distintos supracitados.

\section{Metodologia de pesquisa}

Nesta seção, apresentaremos os objetivos, a natureza e os métodos de pesquisa aplicados no presente trabalho, assim como o contexto, os participantes, os instrumentos utilizados na coleta de dados e os procedimentos para a análise.

\subsection{Objetivos da pesquisa}

Os objetivos desta pesquisa são:

a) Investigar e identificar as crenças e necessidades de estudantes de JLE em relação à escrita;

b) Investigar e identificar as crenças e necessidades de estudantes de $Л \mathrm{LE}$ em relação aos materiais didáticos voltados à escrita;

c) A partir destes, compreender as condutas atuais dos alunos;

d) Como objetivo final, desenvolver materiais didáticos voltados à escrita tomando como base as crenças e necessidades dos estudantes de JLE.

A partir dos objetivos acima propostos, procuramos responder às perguntas de pesquisa a seguir: quais são as crenças e necessidades de estudantes de JLE em relação à escrita e seus materiais didáticos?; como as crenças desses estudantes influenciam suas posturas atuais no estudo de língua japonesa?.

\subsection{A natureza e os métodos da pesquisa}

Nesta pesquisa empregamos o método Split (split method/multiple method), que mescla as abordagens qualitativa e quantitativa (MACKEY; GASS, 2005, p. 164).

O método qualitativo se configura como uma pesquisa interpretativa, além de descritiva e naturalista (DENZIN; LINCOLN, 2006). Assim, este método é adequado para a presente pesquisa, que tem como objetivo interpretar as crenças e necessidades dos participantes a respeito da habilidade de escrita em língua japonesa.

No entanto, utilizamos, como suporte da análise, os dados quantitativos obtidos através de um questionário, com o intuito de reforçar a validade e a confiabilidade dos resultados da pesquisa. 
Como este estudo enfoca as crenças e necessidades apenas de estudantes do curso de Letras-Japonês da Unviersidade de Brasília, classifica-se como um estudo de caso (NUNAN, 1992; JOHNSON, 1992). Segundo Johnson (op. cit., p. 76), em um estudo de caso,

a unidade de análise pode ser um professor, sala de aula, escola, agência, instituição ou uma comunidade. (...) O número de casos é sempre pequeno, porque a essência da abordagem de estudo de caso é um olhar cuidadoso e holístico em casos particulares. O objetivo do estudo de caso é descrever o caso no seu contexto ${ }^{4}$ (tradução nossa).

\subsection{O curso de Letras-Japonês}

O curso de Letras-Japonês da Universidade de Brasília que constituiu o cenário desta pesquisa compõe-se de dois níveis, básico e intermediário, distribuídos em nove semestres. A duração de cada aula é de 1 hora e 40 minutos e cada disciplina é oferecida duas vezes por semana, num total de 30 aulas por semestre.

O nível básico corresponde ao período de quatro semestres, do primeiro até o quarto, e são oferecidas aulas teóricas (com enfoque na gramática, 3 horas e 20 minutos por semana) e práticas (com enfoque na expressão oral e escrita, 3 horas e 20 minutos por semana) separadamente. O nível intermediário, por sua vez, tem início no quinto e termina no oitavo semestre, quando são oferecidas aulas compostas de teoria e prática, cumprindo uma carga horária de 3 horas e 20 minutos por semana, com um total de 100 horas por semestre. O nono semestre é destinado ao projeto de curso (vide apêndice A).

Essa divisão corresponde aos níveis dos livros didáticos adotados pelo curso: "Nihongo Shoho (Japonês básico)" para os quatro primeiros semestres; "Nihongo Chûkyû 1 (Japonês intermediário 1)" para o quinto e sexto semestres; e "Nihongo Chûkŷ̂ 2 (Japonês intermediário 2)" para o sétimo e oitavo semestres, todos publicados pela Fundação Japão.

\subsection{Participantes da pesquisa}

Os participantes desta pesquisa-piloto são estudantes de JLE, alunos de nível intermediário do Departamento de Línguas Estrangeiras e Tradução da Universidade de Brasília (doravante UnB). Os alunos que aceitaram responder ao questionário

4. Texto original: "The unit of analysis (i.e., the case) might also be a teacher, a classroom, a school, an agency, an institution, or a community. (...) The number of cases is always small, however, because the essence of the case-study approach is a careful and holistic look at particular cases. The purpose of a case study is to describe the case in its context" 
foram em um total de 15 (seis alunos do quinto semestre, cinco do sexto semestre, e quatro do sétimo semestre).

Para resguardar as informações pessoais dos participantes desta pesquisa, cada um deles foi representado pelo número atribuído a ele (de 1 a 15) seguido do número do seu semestre, ou seja, $\mathrm{n}^{\circ}$ do aluno $+\mathrm{n}^{\circ}$ do semestre.

\subsection{Coleta dos dados}

Para a coleta dos dados, foram aplicados um questionário (pesquisa quantitativa) e uma entrevista (pesquisa qualitativa). O questionário é formado de um total de 16 perguntas (vide apêndice B) e foi formulado visando uma triangulação metodológica, utilizando três modelos: escolha binária, escala tipo Likert (questionários fechados) e questionário aberto (vide figura 1). Já as entrevistas foram de tipo semiestruturado e foram gravadas com a autorização dos participantes.

\section{Figura 1: modelo de questionário}

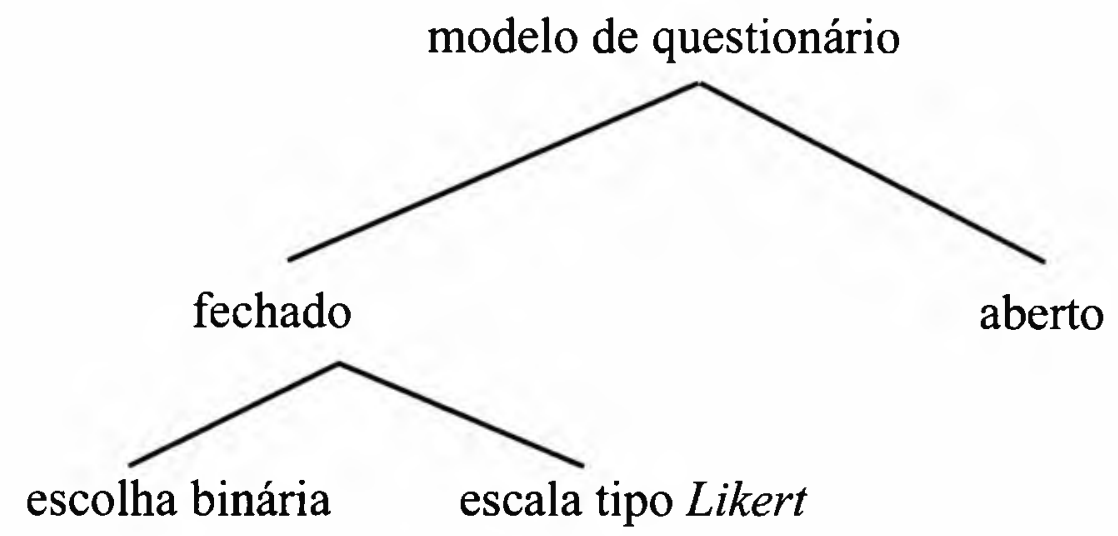

(figura simplificada baseada em YOKOMIZO [2000, p. 166])

\subsection{Procedimento de análise}

Como procedimento de análise dos dados, utilizamos a análise que consiste de um conjunto de procedimentos: identificação, descrição, análise e interpretação (ELLIS; BARKHUIZEN, 2005), para investigarmos as crenças e necessidades dos aprendizes de JLE.

Primeiramente, aplicamos aos participantes o questionário e, depois, a entrevista individual semiestruturada (somente com aqueles participantes que desejaram participar nesta etapa) gravada em áudio. 
No questionário foram investigadas, durante os meses de junho e julho de 2011, as crenças e necessidades dos estudantes de JLE a partir das três seguintes perspectivas: (1) quais as suas crenças gerais em relação ao ato da escrita dentro do estudo de língua japonesa; (2) quais as suas crenças a respeito dos materiais didáticos e aulas voltadas à escrita; e (3) em que situações o estudante sente a necessidade de escrever em japonês.

Em seguida, o autor compilou todos os dados obtidos. Depois, por haver informações que não ficaram claras apenas com o uso do questionário, foram realizadas em julho de 2011 as entrevistas a respeito do conteúdo presente no questionário (apenas com os participantes que desejaram participar na entrevista). Por fim, foram selecionadas e transcritas as partes a serem utilizadas na análise.

Após a coleta dos dados, buscamos identificar e descrever as crenças e necessidades dos participantes a respeito da habilidade de escrita em língua japonesa. Os dados coletados foram agrupados em categorias (CRESWELL, 2009), buscando-se analisar e interpretar as crenças e necessidades acima referidas.

Assim, a nossa análise dos dados seguiu o roteiro abaixo:

a) Coleta dos dados no que se refere às crenças e necessidades dos participantes;

b) Identificação das crenças e necessidades;

c) Descrição das crenças e necessidades;

d) Agrupamento das crenças e necessidades;

e) Análise e interpretação sobre as relações entre as crenças e necessidades a respeito da habilidade de escrita e materiais didáticos.

\section{Resultados da Análise}

Por motivo de espaço, os resultados da análise serão estudados apenas com o foco nas questões $1,2,4,10,13,15$ e 16 do questionário.

\subsection{Análise dos resultados quanto à importância (necessidade) das quatro habilidades (Questão 1)}

$\mathrm{Na}$ questão 1 do questionário foi pedido aos participantes que enumerassem as quatro habilidades na ordem de importância que lhes atribuíam, organizando estatisticamente o resultado de acordo com o número de participantes e a média dos valores obtida para cada habilidade. Abaixo se encontram os resultados obtidos quanto à importância atribuída pelos participantes às quatro habilidades (vide quadro 1). 


\section{Quadro 1: Importância atribuída pelos estudantes de Jle da Unb às quatro habilidades}

\begin{tabular}{|c|c|}
\hline Grau de importância atribuída & Habilidade \\
\hline $1^{\mathrm{a}}$ habilidade mais importante & Compreensão auditiva $($ kiku $)$ \\
\hline $2^{\mathrm{a}}$ habilidade mais importante & Fala $($ hanasu $)$ \\
\hline $3^{\mathrm{a}}$ habilidade mais importante & Leitura $($ yomu $)$ \\
\hline $4^{\mathrm{a}}$ habilidade mais importante & Escrita $(\mathrm{kaku})$ \\
\hline
\end{tabular}

Foi descoberto que, para os estudantes de JLE da UnB, a escrita é a habilidade menos importante dentre todas as quatro. Na Figura 2 abaixo, são mostradas as médias dos valores obtidas para o grau de importância de cada uma das quatro habilidades.

Figura 2: Grau de importância das quatro habilidades - média dos valores - (questão 1)

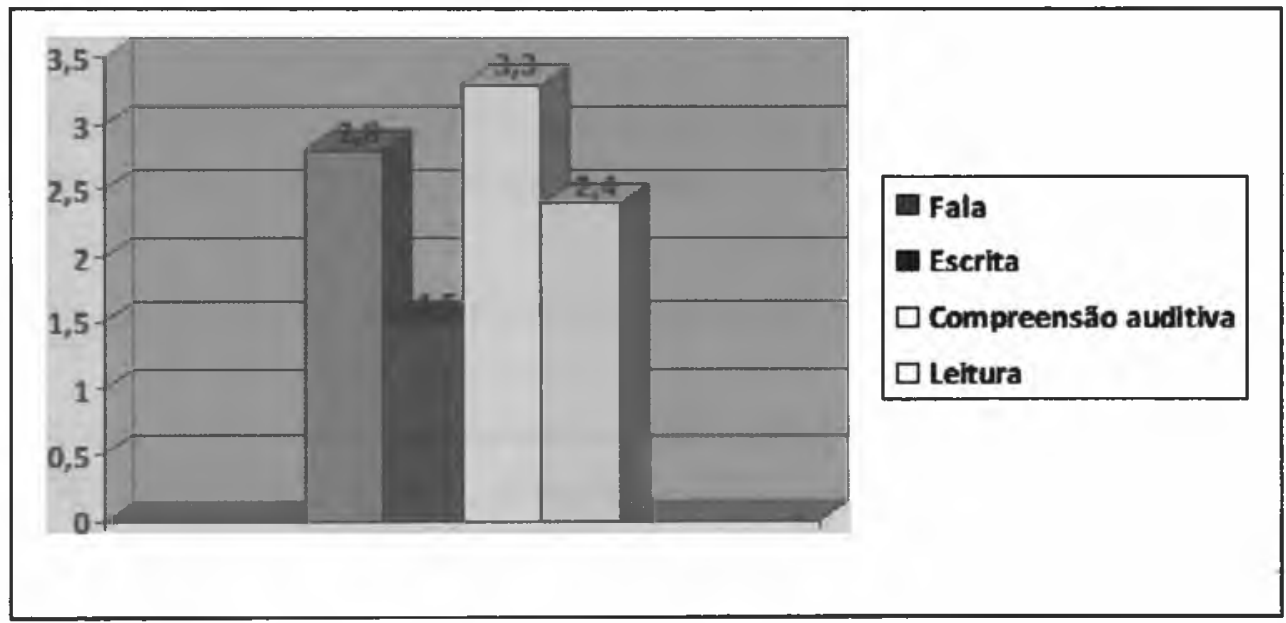

Observação: Muito importante $=>4$ pontos; Importante $=>3$; Mediano $=>2$ pontos; Pouco importante $=>1$ ponto. Calculado com arredondamento do resultado. Pontuação máxima $=4$ pontos; pontuação mínima $=1$ ponto.

Tomando-se o grau de importância das quatro habilidades em relação ao número de participantes a escolher cada opção, foram obtidos os seguintes resultados: 


\section{Figura 3: Grau de importância das quatro habilidades - pelo número de participantes - (Questão 1)}

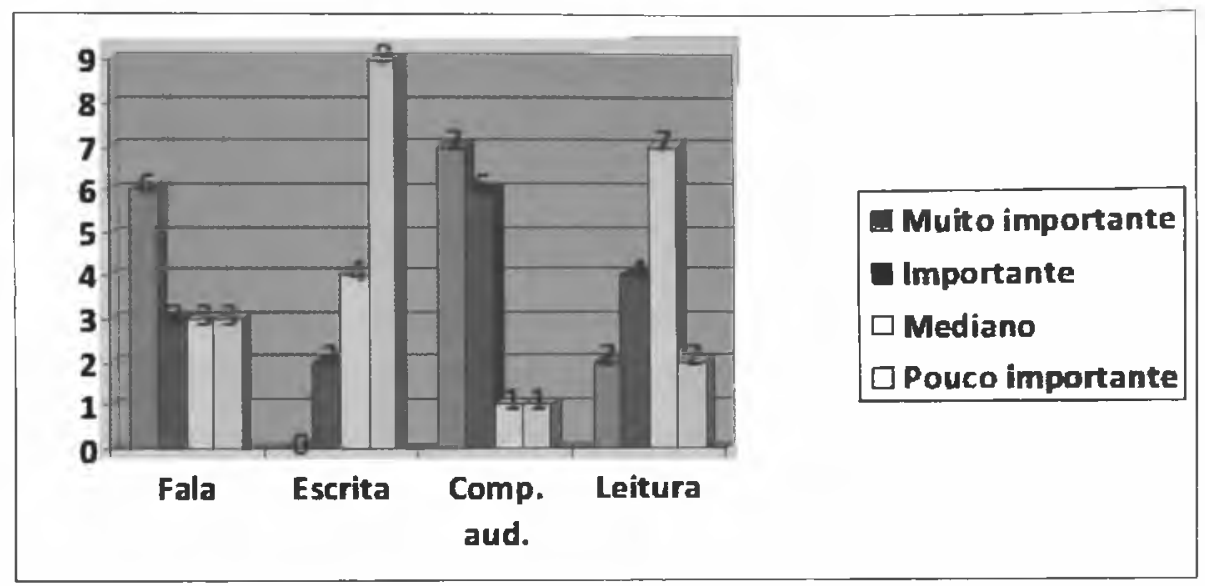

Obs.: Comp. aud. $=$ Compreensão auditiva.

Quanto à escrita, não houve nenhum estudante que a tenha escolhido como "muito importante" e o maior número deles escolheu como "pouco importante" Ou seja, pode-se dizer que, no ambiente de JLE, a escrita na língua japonesa não é considerada importante, não havendo senso de necessidade de desenvolver essa habilidade.

Entretanto, os participantes parecem gostar de escrever em língua japonesa. Dentre os 15 participantes, apenas 2 responderam que não gostam de escrever em japonês (Questão 4 do questionário).

A seguir, as crenças dos alunos que responderam como "gosto de escrever":

(1) Apesar de ser dificil e ter dificuldades em memorizar tantos kanji, seus traços, significados e leituras, eu gosto muito. Acho muito interessante escrever por meio de ideogramas. (No. 1-6)

(2) Gostar, eu gosto, mas tenho grande dificuldade em lembrar todas as partes de um kanji. (No. 2-6)

(3) Apesar da dificuldade do domínio das estruturas e kanji, gosto de escrever em japonês. (No. 5-6)

Já as crenças dos alunos que responderam como "não gosto de escrever":

(4) Não gosto de escrever. Porque nunca tenho ideia do que escrever. (No. 11-7)

(5) Não. Raramente os temas propostos para escrita são interessantes, o que torna a atividade improdutiva e entediante. (No. 13-7) 
O que se pode considerar a partir destes resultados é que há uma premissa de que é necessário memorizar as estruturas gramaticais e kanji para se poder escrever. Mas, caso se realizem, na sala de aula ou na extraclasse, atividades de escrita que se baseiem em pesquisas pela internet, dicionários online, ferramentas de tradução online e outras fontes que não apenas materiais de referência impressos, é possível que isso leve a uma autonomia no aprendizado. Ou seja, é necessário orientar no sentido de "usar recursos para escrever" em vez de "memorizar para escrever"

\subsection{Em que situações você sente a necessidade de escrever em japonês? (Questão 13)}

Na questão 13 do questionário, as respostas mais dadas foram "dever de casa" e "exercícios". Relacionadas às aulas de língua japonesa, as demais respostas mais comuns foram "teste de japonês" em quarto lugar e "nas aulas" em quinto (vide quadro 2).

Quadro 2: Em que situações se sente a necessidade ee escrever em japonês (Questão 13)

\begin{tabular}{|c|l|c|}
\hline Ordem & \multicolumn{1}{|c|}{ Situação } & $\begin{array}{c}\text { Número de } \\
\text { participantes } \\
\text { Múltipla escolha } \\
\text { possível) }\end{array}$ \\
\hline 1 & Dever de casa, exercícios & 8 \\
\hline 2 & Bate papo pela internet & 5 \\
\hline 3 & E-mail & 4 \\
\hline \multirow{2}{*}{4} & Cartas & 3 \\
\cline { 2 - 3 } & Teste de Japonês & 3 \\
\hline \multirow{3}{*}{5} & Redes sociais (facebook e outras) & 2 \\
\cline { 2 - 3 } & Pesquisas na internet & 2 \\
\cline { 2 - 3 } & Nas aulas & 2 \\
\hline \multirow{3}{*}{} & Redações & 1 \\
\cline { 2 - 3 } & Documentos & 1 \\
\cline { 2 - 3 } & Monografias & 1 \\
\cline { 2 - 3 } & Quando não se sabe a leitura do kanji (no dicionário & 1 \\
\hline \multirow{3}{*}{6} & eletrônico) & 1 \\
\cline { 2 - 3 } & Dicionário online & 1 \\
\cline { 2 - 3 } & Treino de digitação em japonês & 1 \\
\cline { 2 - 3 } & Sites de língua japonesa & 1 \\
\cline { 2 - 3 } & Preenchimento de fichas de inscrição & 1 \\
\cline { 2 - 3 } & Texto para uso no concurso de oratória & 1 \\
\cline { 2 - 3 } & Tradução de letras de músicas & 1 \\
\hline
\end{tabular}


Pode-se observar que grande parte das situações em que os estudantes de JLE escrevem em japonês é relacionada ao estudo e às aulas de japonês. $O$ que se pode inferir disto é que as situações e a necessidade de escrever em japonês para esses alunos estão limitadas ao estudo e a aulas de japonês.

Em seguida, o que merece atenção são a segunda e a terceira situações mais votadas, "bate papo pela internet" e "e-mail", respectivamente; e também outras opções como a quinta, "redes sociais (facebook e outras)", que são usos pela internet, ou seja, ações que requerem digitação em vez de escrita a mão.

Isso sugere que tem aumentado o número de alunos de JLE que usam teclados para escrever em japonês em vez de escrever a mão. Novamente, isso quer dizer que é requerido dos professores de língua japonesa que se desenvolvam materiais didáticos online e outros meios online, não apenas materiais de referência impressos.

\subsection{Que tipo de tópicos/assuntos você escreve (digita) em japonês no dia-a- dia? (Questão 15)}

A seguir, encontram-se os resultados da questão15.

\section{Quadro 3: Que tipo de tópicos/assuntos você escreve (digita) em japonês no dia-a-dia? (Questão 15)}

\begin{tabular}{|l|l|c|}
\hline & \multicolumn{1}{|c|}{ Tópicos / assuntos } & \multicolumn{1}{|c|}{$\begin{array}{c}\text { Número de } \\
\text { participantes } \\
\text { (Múltipla escolha } \\
\text { possível) }\end{array}$} \\
\hline a) & Nenhum específico & 3 \\
\hline b) & Comunicação com o(s) professor(es) & 3 \\
\hline c) & Assuntos cotidianos no chat & 3 \\
\hline d) & $\begin{array}{l}\text { Assuntos cotidianos através de redes sociais } \\
\text { (facebook, twitter, etc.) }\end{array}$ & 3 \\
\hline e) & $\begin{array}{l}\text { Assuntos cotidianos (tecnologia, comida, } \\
\text { relacionamento, notícias, etc.) }\end{array}$ & 3 \\
\hline f) & Monografia; texto para apresentação oral & 2 \\
\hline g) & Dever de casa & 2 \\
\hline
\end{tabular}

As opções dadas pelos alunos de JLE na questão 15 (vide quadro 3) podem ser agrupadas nas duas seguintes categorias: (1) opções relacionadas ao estudo 


\begin{tabular}{|l|c|l|c|}
\hline $\begin{array}{l}\text { Assuntos referentes ao } \\
\text { conteúdo e objetivos do curso } \\
\text { de japonês }\end{array}$ & 1 & Linguística Aplicada & 1 \\
\hline Notícias sobre o Japão & 1 & Ensino de LE & 1 \\
\hline Fenômenos sociais no Japão & 1 & $\begin{array}{l}\text { Diferenças culturais } \\
\text { entre Brasil e Japão }\end{array}$ & 1 \\
\hline Psicologia & 1 & $\begin{array}{l}\text { Legislação } \\
\text { Educacional Japonesa }\end{array}$ & 1 \\
\hline Antropologia & 1 & Documentos & 1 \\
\hline $\begin{array}{l}\text { Questões da atualidade } \\
\text { mundial }\end{array}$ & 1 & & \\
\hline
\end{tabular}

Os participantes não escrevem diariamente nem sentem a necessidade de escrever sobre esses tópicos aqui apresentados. No entanto, pode-se dizer que isto ocorre porque eles não sentem haver, normalmente, necessidade ou oportunidade de escrever em japonês, mas também reflete o desejo dos alunos de JLE de escrever nesse idioma sobre diversos temas.

\subsection{O grau de importância dado à escrita dentre as quatro habilidades e crenças a seu respeito (Questão 2)}

Nesta seção, verificaremos as crenças dos participantes desta pesquisa relativas à habilidade da escrita. Apresentaremos as crenças dos estudantes que a classificaram como a quarta (ou seja, pouco importante), terceira (mediano) e segunda (importante) em ordem de importância dentre as quatro habilidades.

\section{Crenças dos participantes que consideram a habilidade de escrita pouco importante ( $4^{a}$ colocação):}

(6) Acho que o mais importante é ter compreensão do que é dito, para que haja comunicação, posteriormente, a capacidade de se expressar. Creio que a escrita é a última a ser refinada, depois que se possuir certos domínios sobre as outras habilidades que são mais práticas. (No.5-6)

(7) O mais importante pra mim é se fazer entender de forma prática e rápida, ou seja, intermédio da fala. (...) Quanto a ler e escrever, acredito que a escrita se desenvolve a partir da leitura. (No. 7-5)

(8) O meu maior interesse na lingua é poder compreender material em japonês, por isso dei prioridade a ouvir e depois ler. Falar e escrever estão em segundo plano. (No. 9-5) 
de japonês; (2) opções relacionadas a atividades do dia-a-dia. Principalmente na categoria concernente a atividades diárias, pode-se observar muitas atividades relativas à internet, digitando-se em japonês.

Os resultados da questão 15 também se assemelharam muito aos da questão 13 (em que situações você sente a necessidade de escrever em japonês?). Ou seja, para os participantes, o que eles escrevem em japonês no dia-a-dia é aquilo que eles acham necessário escrever (em japonês).

A resposta "nenhum específico" ter sido a primeira mais frequente também é uma questão importante. Pois, pode-se inferir que os alunos não têm oportunidades ou motivos para escrever em japonês.

\subsection{Tópicos/assuntos sobre os quais gostaria de escrever futuramente (Questão 16)}

$\mathrm{Na}$ questão 16 grande variedade de tópicos foi dada (vide quadro 4).

\section{Quadro 4: tópicos/assuntos sobre os quais gostaria de escrever futuramente (questão 16)}

\begin{tabular}{|l|c|l|c|}
\hline \multicolumn{1}{|c|}{ Tópico / Assunto } & $\begin{array}{c}\text { Número de } \\
\text { participantes } \\
\text { (Múltipla } \\
\text { escolha } \\
\text { possível) }\end{array}$ & Tópico / Assunto & $\begin{array}{c}\text { Número de } \\
\text { participantes } \\
\text { (Múltipla } \\
\text { escolha } \\
\text { possível) }\end{array}$ \\
\hline Filmes & 3 & Militarismo e defesa & 1 \\
\hline Nenhum específico & 2 & $\begin{array}{l}\text { Comunicação com } \\
\text { japoneses }\end{array}$ & 1 \\
\hline Comidas típicas & 1 & Temas mais abstratos & 1 \\
\hline Pontos turísticos do Japão & 1 & Contos & 1 \\
\hline $\begin{array}{l}\text { Pontos históricos relevantes do } \\
\text { Japão }\end{array}$ & 1 & Arte e design & 1 \\
\hline $\begin{array}{l}\text { Eventos históricos relevantes } \\
\text { do Japão }\end{array}$ & 1 & Poesia & 1 \\
\hline Religião & 1 & Música & 1 \\
\hline Música e história do Brasil & 1 & História & 1 \\
\hline Artes marciais japonesas & 1 & Política & 1 \\
\hline $\begin{array}{l}\text { Como a internet mudou o } \\
\text { ensino de japonês }\end{array}$ & 1 & Economia & 1 \\
\hline $\begin{array}{l}\text { Relações entre Brasil e Japão } \\
\text { (economia, atualidades, etc.) }\end{array}$ & 1 & Literatura & \\
\hline
\end{tabular}


(9) Conseguir receber e interpretar informações me soa como prioridade, não desmerecendo as outras habilidades, lógico. (No. 10-5)

(10) A partir de ouvir e ler é possivel desenvolver as habilidades de fala e escrita naturalmente. (No. 13-7)

\section{Crenças dos participantes que consideram mediana a habilidade de escrita ( $3^{\mathrm{a}}$ colocação):}

(11) Coloquei 3 em escrever porque acho que, para escrever bem, preciso primeiro ouvir e falar bem. (No.1-6)

(12) Ler-acredito que ler é o mais importante, porque desenvolve a escrita. (No.11-7)

(13) É possivel dizer que através do falar/ouvir língua alvo se aprende de forma mais fácil a ler e a escrever. (No. 14-7)

(14) Eu acredito que, para escrever bem, é necessário ler bem e muito. (No. 15-5)

\section{Crenças dos participantes que consideram a habilidade de escrita importante ( $2^{\text {a }}$ colocação):}

(15) Porque, quando nem se tem uma boa habilidade de fala, a escrita pode ser usada para expressar a mensagem desejada. (No. 3-6)

(16) Para adaptar-se ao sistema escrito da língua, que difere em muito do sistema romano. (No. 6-5)

É interessante notar que o aluno no. 6-5 colocou a escrita como a segunda habilidade mais importante por conta do sistema de escrita japonês ser completamente diferente daquele usado na língua materna (sistema romano).

Por outro lado, podemos agregar as crenças dos estudantes que acham a escrita pouco importante nas duas categorias abaixo:

a) Para se conseguir escrever é necessário, primeiramente, ter boa compreensão auditiva e falar (pode-se dizer que, por essa razão, a escrita foi colocada na última colocação);

b) As competências receptivas (input: audição e leitura) são pré-requisitos para as competências de produção (output: fala e escrita).

Ou seja, isto mostra que, para o estudante, a escrita demanda, primeiramente, que se recebam e que se estudem (nas aulas) os caracteres e padrões de sentenças, para que se possa, por fim, expressar os caracteres e sentenças aprendidos e assimilados na memória. Também pode-se perguntar se isso envolve uma postura do aluno de não tentar escrever até que se consiga ler (embora seja necessário investigar o que seria "conseguir ler" para o aluno). A partir destes resultados, vê-se 
necessário indicar aos alunos que é possível escrever utilizando vários recursos, mesmo que não se consiga ler bem.

\subsection{Que tipo de material de escrita você desejaria? (Questão 10)}

Na questão 10 do questionário foi perguntado aos alunos que tipo de material de escrita gostariam de usar, investigando as necessidades quanto a materiais didáticos para a escrita. Abaixo são apresentadas várias respostas relevantes dadas pelos participantes.

(17) Materiais que me fizessem não só repetir várias vezes os Kanji, mas que também me oferecessem associações para assimilar e memorizar melhor tantos Kanji e tantas leituras. (No. 1-6)

(18) Observo uma certa carência em materiais para usuários da lingua portuguesa, pois a maioria dos materiais de consulta vem na língua inglesa. (No. 3-6)

(19) $\dot{E}$ dificil dizer, mas um material onde o próprio aluno possa produzir, onde possa praticar o que foi aprendido, fazer a tradução português-japonês/japonês-português. (No. 4-6)

(20) Materiais diferentes do "Nihongo Shoho", trechos de animações, livros literários, músicas, mangás. (No. 9-5)

(21) Um material que fosse, de algum modo, mais contextualizado, talvez trabalhando temas atuais. (No. 10-5)

(22) Textos mais complexos e que demandem maior tempo de estudo, mas que, ao mesmo tempo, usem vocabulários e kanji usuais, que se mostrem úteis. Os textos devem ser interessantes também. Quando o texto é interessante, desafiador e que demonstra utilidade, é motivador estudá-lo. (No. 13-7)

(23) Gostaria de usar em sala de aula materiais que partissem do principio da abordagem comunicativa, onde o material usado tende a ser, ao máximo, próximo do japonês (usado realmente). (No. 14-7)

Como resultado da análise dos resultados vistos acima, podemos listar três possibilidades de materiais didáticos que os estudantes de JLE desta pesquisa desejariam ter:

a) Materiais didáticos com explicações na língua materna (língua portuguesa), pois estimulam o estudo;

b) Como não há muitas situações fora de sala de aula em que se possa utilizar a língua japonesa, materiais feitos pensando em um contexto (que realmente se encontre no Japão) não tão fácil e que não sejam exercícios a serem repetidos de forma automática;

c) Materiais de uso prático, que possam ser usados assim que se chegue ao Japão, abordando assuntos atuais e relevantes. 
O que se pode concluir disto é que os alunos de JLE da UnB acreditam que os materiais para escrita devem estar escritos na língua materna para estimular o estudo, não gostam do método de estudo audiolingual, e têm a crença de que tópicos atuais e materiais de uso prático devem ser mais focados.

\section{Conclusões}

Como resultado do estudo das crenças e das necessidades dos estudantes de JLE acerca da escrita e de materiais para escrita, na atual pesquisa ficaram claros os pontos abaixo:

a) Quanto às crenças sobre escrita, os estudantes de JLE desta pesquisa acreditam que $o$ ato da escrita em japonês no dia-a-dia não é tão importante se comparado com as outras habilidades (fala, compreensão auditiva e leitura);

b) Foi muito observada a crença de que, para se conseguir escrever é preciso, primeiramente, ter boa compreensão auditiva e saber falar. Por essa razão, a escrita foi a habilidade com pior classificação;

c) No entanto, os alunos gostam de escrever em japonês (embora não sintam necessidade). Pode-se inferir tal fato pela grande variedade de tópicos sobre os quais eles gostariam de escrever (Questão 16);

d) Os resultados das questões "Em que situação (contexto) você sente fortemente a necessidade de escrever (digitar) em japonês?" (Questão 13) e "Sobre que tipo de tópicos/assuntos você escreve em japonês no dia-a-dia?" (Questão 15) foram bastante parecidos. Foram assuntos do cotidiano e assuntos relacionados ao estudo de japonês (dever de casa, exercícios, etc.), possivelmente pela sala de aula ser o principal lugar (dentro do ambiente de JLE) em que o aluno tem a experiência da língua japonesa. Porém, como os estudantes que digitam em japonês por meio de e-mail, bate papos online e redes sociais como facebook chamam a atenção, pode-se supor que as oportunidades fora de sala de aula de se digitar em japonês tendem a aumentar futuramente;

e) Há uma carência de materiais para escrita e de oportunidades de escrever que aumentem a motivação dos estudantes de JLE. Como se verificou na questão 4, os alunos que não gostam de escrever em japonês não têm ideia do que escrever. Ou então, os temas dados não são interessantes. Pode-se supor que isso leva à perda do interesse em escrever;

f) Quanto às necessidades de materiais didáticos, ficou claro que os estudantes acreditam que livros com explicações na língua materna estimulam o estudo da escrita. E como fora de sala de aula quase não há situação em que se possa usar o japonês, eles também gostariam de ter materiais de uso prático, criados 
tendo como base situações reais encontradas no Japão, em vez de exercícios de repetição maquinal.

O que se pode concluir a partir destes resultados é que, para os estudantes de JLE desenvolverem sua habilidade da escrita, o mais rápido possível são necessários:

a) Materiais didáticos e oportunidades de aumentar a motivação dos estudantes para que se escreva (digite) em japonês diariamente;

b) Materiais didáticos, oportunidades e exercícios para se digitar, não apenas escrever a mão;

c) Não apenas um só material padronizado, mas materiais didáticos que atendam às necessidades individuais de cada estudante, devido à variedade de tópicos e assuntos a se abordar;

d) Desenvolvimento de materiais didáticos que incluam materiais online, não apenas materiais impressos;

e) Desenvolvimento de materiais voltados não apenas para atividades dentro de sala de aula, como também atividades para fora de sala (aulas online, buscas na internet, dicionários online, ferramentas de tradução online, e-mail, informações sobre como escrever um blog, etc.), visando a autonomia por parte dos estudantes.

Devido à globalização e à difusão da internet, o modelo de ensino e de estudo da língua japonesa tem mudado bastante. Por meio da internet, os estudantes de JLE têm fácil acesso a informações vindas do Japão. Ou seja, não há fronteiras na internet para o JLE (Japonês como LE) e o JL2 (Japonês como L2) no desenvolvimento de materiais didáticos online também se encontra neste ponto. Tais materiais são melhores para atender às necessidades e à diversificação dos estudantes, assim como às questões de gramática de cada um (NODA, 2005; KOBAYASHI, 2005). No entanto, embora se possa dizer que não haja fronteiras na internet para o JLE e o JL2, na realidade há grandes diferenças no ambiente atual do estudante e do professor. Portanto, espera-se que as crenças e necessidades dos estudantes de JLE a respeito da escrita apresentadas neste trabalho possam servir de referência, mesmo modestamente, para o desenvolvimento de tais materiais

5. Nos Estudos da Aquisição-Aprendizagem de Línguas Estrangeiras, atualmente, as noções LE (língua estrangeira) e L2 (segunda língua) diferenciam-se com base no contexto onde se aprende uma língua estrangeira: caso se aprenda o japonês, por exemplo, nos países ou comunidade em que se fala/utiliza essa mesma língua como meio de comunicação, considera-a como segunda língua (L2); caso se aprenda o japonês nos países ou comunidade em que não se fala/utiliza essa mesma língua como meio de comunicação, considera-a como língua estrangeira (LE). 
didáticos online. Pode-se esperar, também, que os professores de JLE reflitam o ensino da escrita em JLE, tendo como referência os resultados desta pesquisa, que mostram que os alunos classificam a escrita como a última das habilidades em ordem de importância.

Neste trabalho, como pesquisa-piloto com os estudantes de nível intermediário da UnB, pesquisaram-se as crenças e necessidades dos alunos em relação à escrita. Futuramente, serão necessárias pesquisas acerca das crenças e necessidades dos alunos de JLE quanto à escrita em outras universidades do Brasil, escolas de idiomas e também em outros países. Além disso, para a criação de materiais didáticos online, é importante que se considerem os resultados de pesquisas com os alunos de JLE e JL2, comparando-se as crenças e necessidades que os estudantes têm conforme o ambiente de estudo da língua japonesa.

Como este trabalho se tratava de uma pesquisa-piloto e estudo de caso, o número de participantes foi limitado. Em uma próxima etapa, é necessário realizar a mesma pesquisa com um número maior de estudantes, pois não podemos generalizar os resultados. É desejável, também, que, para podermos compreender o processo de aquisição de línguas estrangeiras, sejam realizadas pesquisas semelhantes, estudando individualmente cada uma das outras habilidades (fala, leitura e compreensão auditiva).

\section{Referências}

ALVAREZ, M. L. O. Crenças, Motivações e Expectativas de Alunos de um Curso de Formação Letras/Espanhol. In: ALVAREZ, M. L. O.; SILVA, K, A. da (Orgs.). Linguística Aplicada: Múltiplos Olhares. 1. ed., Campinas-São Paulo: Pontes Editores, 2007, p. 191-231.

BARCELOS, A. M. F. Metodologia de Pesquisa das Crenças sobre Aprendizagem de Línguas: estado da arte. Revista Brasileira de Linguística Aplicada, v. 1, n. 1, p. 71-92, 2001.

Crenças sobre aprendizagem de línguas, Lingüística Aplicada e Ensino de Línguas. Linguagem \& Ensino, v. 7, n. 1, p. 123-156, 2004.

BARCELOS, A. M. F. Narrativas, crenças e Experiênciasde Aprender Inglês. Linguagem \& Ensino, v. 9, n. 2, p. 145-175, 2006.

Crenças sobre Ensino e Aprendizagem de Línguas: Reflexões de uma Década de Pesquisa no Brasil. In: ALVAREZ, M. L. O.; SILVA, K, A. da (Orgs.). Linguística Aplicada: múltiplos olhares. 1. ed., Campinas-São Paulo: Pontes Editores, 2007, p. 27-79.

Reflexões, Crenças e Emoções de Professores e da Formadora de Professores. In: BARCELOS, A. M. F.; COELHO, H. S. H. (Orgs.). Emoções, reflexões e (trans) form(ações) de alunos, professores e formadores de professores de línguas. 1. ed., Campinas-SP, 2010, p. 57-81.

CONCEIÇÃO, M. P. Vocabulário e Consulta ao Dicionário: Analisando as Relações entre Experiências, Crenças e Ações na Aprendizagem de LE. Belo Horizonte-MG, 2004, 287 
f. Tese (Doutorado em Linguística Aplicada) - Faculdade de Letras, Universidade de Minas Gerais.

CRESWELL, J. W. Research Design: Qualitative, Quantitative, and Mixed Methods Approaches. 3. ed. Thousand Oaks, California: SAGE Publications, 2009.

DENZIN, N. K.; LINCOLN, Y. S. A Disciplina e a Prática da Pesquisa Qualitativa. In: DENZIN, N. K.; LINCOLN, Y. S. (Orgs). O Planejamento da Pesquisa Qualitativa: teorias e abordagens. Tradução de Sandra Regina Netz. 2. ed., Porto Alegre: Artmed, 2006, p. 15-41.

ELLIS, R.; BARKHUIZEN, G. Analysing Leaner Language. 1. ed. Oxford: Oxford University Press, 2005.

HORWITZ, E. K. Surveying Student Beliefs about Language Learning. In: WENDEN, A. L.; RUBIN, J. (Orgs.). Leaner Strategies in Language Learning. 1. ed., Londres: PrenticeHall International, 1987, p. 119-129.

JOHNSON, D. M. Approaches to Research in Second Language Learning. 1. ed., Longman: Nova York, 1992.

KALAJA, P. Student beliefs (or Metacognitive Knowledge) about SLA Reconsidered. International Journal of Applied Linguistics, v. 5, n. 2, 1995, p. 191-204.

KAWAGUCHI, Y; YOKOMIZO, S. Seichô Suru Kyôshi no Tame no Nihongo Kyôiku Guide Book (jô) (Guia do ensino da língua japonesa para o crescimento de professores [volume 1]). 1. ed., Tóquio: Hitsuji Shobô, 2005.

KOBAYASHI, M. Communication ni Yakunitatsu Nihongo Kyôiku Bumpô (Gramática pedagógica da língua japonesa que serve para a comunicação). In: NODA, H. (Org.). Communikeshon no Tame no Nihongo Kyôiku Bunpô (Gramática pedagógica da língua japonesa para a comunicação). 1. ed. Tóquio: Kuroshio Shuppan, 2005, p. 23-41.

LARSEN-FREEMAN, D.; LONG, M. H. An Introduction to Second Language Acquisition Research. 1. ed. Essex: Longman Group UK Limited, 1991.

MACKEY, A.; GASS, S. M. Second Language Research: Methodology and Design. 1. ed., New Jersey: Lawrence Erlbaum Associates, 2005.

McKAY, S. L. O Professor Reflexivo: Guia para Investigação do Comportamento em Sala de Aula. Trad.: Renata Lea F. Oliveira. 1. ed., São Paulo: Special Books Services Livraria, 2003 (Título original: Teaching listening in the language classroom).

MUKAI, Y. JFL Nihongo Gakushûsha no Biriifu Kenkyû: Nihongo de "Kaku (Utsu)" Koto Ni Kanshite no Yobi Kenkyû (Crenças dos aprendizes de japonês como LE: um Estudo Preliminar sobre a Habilidade De "Escrita (digitada)" em japonês. Brasilia nihongo fukyû kyôkai kyôkaishi (Revista da Associação de Estudos da Língua Japonesa de Brasília), v. 23, set. 2011, p. 34-50.

NODA, H. Communication no Tame no Nihongo Kyôiku Bumpô no Sekkeizu (Escopo da Gramática Pedagógica da Língua Japonesa para a Comunicação). In: NODA, H. (Org.). Communikêshôn no tame no nihongo kyôiku bunpô (Gramática Pedagógica Da Língua Japonesa para a Comunicação). 1. ed. Tóquio: Kuroshio Shuppan, 2005, p. 1-20.

NUNAN, D. Research Methods in Language Learning. 1. ed., Cambridge: Cambridge University Press, 1992. 
PAJARES, M. F. Teachers' Beliefs and Educational Research: Cleaning up a Messy Construct. Review of Educational Research, v. 62, n. 3, p. 307-332, 1992 (fall).

RICHARDS, J. C.; LOCKHART, C. Reflective Teaching in Second Language Classrooms. 1. ed., Nova York: Cambridge University Press, 1996.

SELIGER, H. W.; SHOHAMY, E. Second Language Research Methods. 1. ed. Oxford: Oxford University Press, 1989.

SILVA, K. A. da. (Org.). Crenças, Discursos \& Linguagem - volume 1. 1. ed., Campinas-São Paulo: Pontes editores, 2010.

THE JAPAN FOUNDATION (Org.). Nihongo Shoho. 1. ed. Tóquio: Bonjinsha, 1981. Nihongo Chûkyû I. 1. ed. Tóquio: Bonjinsha, 1990.

Nihongo Chûkyû II. 1. ed. Tóquio: Bonjinsha, 1996.

Dai Ikkan Nihongo Kyôshi no Yakuwari/Course Design (O Papel dos Professores da Língua Japonesa/Course Design [volume 1]). 1. ed., Tóquio: Hitsuji Shobô, 2006.

TUDOR, I. Learner-centredness as Language Education. 1. ed., Cambridge: Cambridge University Press, 1996.

VIEIRA-ABRAHÃO, M. H. A Formação Inicial e o Desenvolvimento Profissional do Professor de Línguas Estrangeiras: Práticas E Pesquisas. Horizontes de Linguística Aplicada. Ano 5, n. 2, p. 6-23, dez. 2006.

WENDEN, A. L. An Introduction to Metacognitive Knowledge and Beliefs in Language Learning: Beyond The Basics. System, v. 27, 1999, 435-441.

YOKOMIZO, S. Nihongo Kyôshi no tameno Action Research (Pesquisa-Ação para Professores da Língua Japonesa). 1. ed., Tóquio: Bonjinsha, 2000.

YUI, K. Kaku tame no Nihongo Kyôiku Bumpô (Gramática Pedagógica da Língua Japonesa para a Escrita). In: NODA, H. (Org.). Communication no tame no nihongo kyôiku bumpô (Gramática pedagógica da língua japonesa para a comunicação). 1. ed. Tóquio: Kuroshio Shuppan, 2005, p. 187-206. 


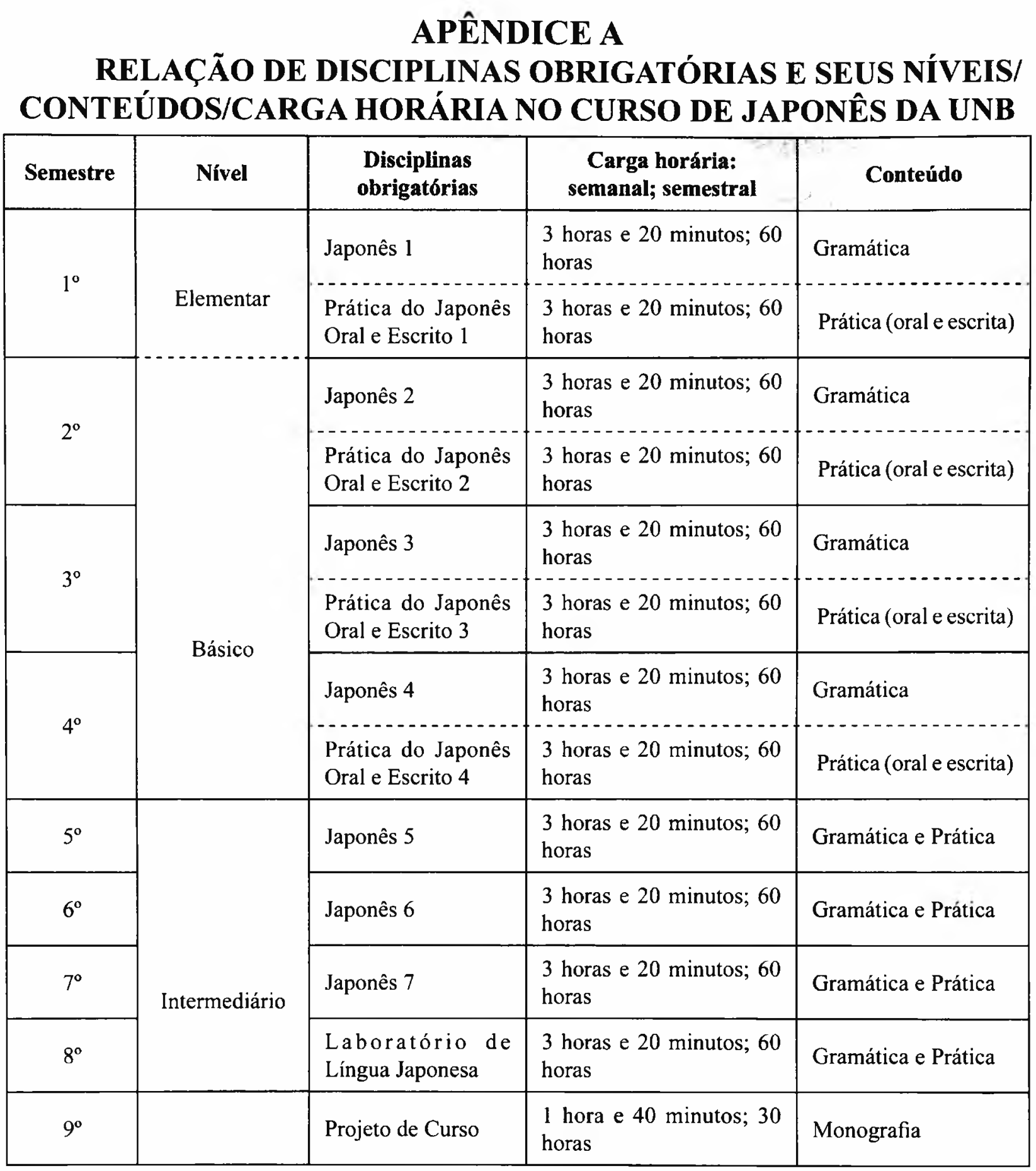




\title{
APÊNDICE B
}

\section{QUESTIONÁRIO SOBRE \\ A HABILIDADE DE "ESCRITA" EM LÍNGUA JAPONESA}

\begin{abstract}
Nós estamos realizando uma pesquisa sobre materiais didáticos referentes à habilidade de "escrita" em língua japonesa por parte dos alunos do mesmo idioma. Gostaríamos de ouvir sua opinião sincera sobre "escrever (digitar)" em língua japonesa no dia-a-dia inclusive no contexto escolar. A presente pesquisa tem como objetivo enriquecer e desenvolver materiais sobre a escrita em japonês. Por favor, responda às 16 perguntas. Informamos que utilizaremos os resultados obtidos neste questionário apena para o fim da nossa pesquisa. Todas as informações dadas por você serão feitas de forma anônima, ou seja, seu nome verdadeiro não será revelado. Desde já agradecemos sua colaboração.
\end{abstract}

\section{[Pesquisadores]}

Universidade de Brasília

Instituto de Letras

Departamento de Línguas Estrangeiras e Tradução

Curso de Letras-Japonês

Prof. Dr. Yûki Mukai

yuki@unb.br

İstanbul Bilgi University (Universidade de Istambul Bilgi)

Instrutora de Língua Japonesa

Profa. Tomoyo Özerhan

tomoyo@bilgi.edu.tr

Obs.:

O presente estudo é um trabalho do grupo de pesquisa sobre a "Elaboração e uso de material on-line da língua japonesa para a comunicação", auxiliado subsidiado pela pesquisa científica (A) a partir de 2009 a 2013 (no. do projeto: 21242012), cuja representante do grupo é a Profa. Dra. Mina Kobayashi, da Universidade de Waseda - Japão.

Data de realização da entrevista:

Horário:

Local:

Entrevistador: 


\section{$<$ Informações sobre o background do participante>}

Nome:

Matrícula:

Instituição onde estuda japonês:

Semestre/ano atual:

Língua materna:

Sexo:

Idade:

Aluno regular do curso de Japonês: $\operatorname{Sim}(\quad$ ) Não ( )

(Se "não", escreva seu curso.)

Você já tinha aprendido japonês antes de ingressar nesta instituição?:

Sim ( ) Não ( )

(Se "sim", onde e quanto tempo?:

Total de horas/período de aprendizagem da língua japonesa até agora:

Nível de seu japonês (se tiver algum certificado, escreva o nível e o ano de obtenção):

Você já morou no Japão?: SIM ( ) NÃO ( )

Se "sim", quantas vezes e por quanto tempo?

Língua(s) aprendida(s) antes do japonês, seu nível e total de horas/período: 
Com que frequência, com quem e onde você usa o japonês fora da sala de aula/ universidade?:

\section{[Questionário]}

Parte 1: Habilidade de "escrita" ${ }^{6}$ no ensino-aprendizagem de língua japonesa

1. Dentre as quatro habilidades linguísticas (falar, escrever, ouvir, ler), qual habilidade é mais importante para você no ensino-aprendizagem de língua japonesa? Coloque o número 1 para a habilidade que você considere mais importante e 4 para habilidade que você considere menos importante.

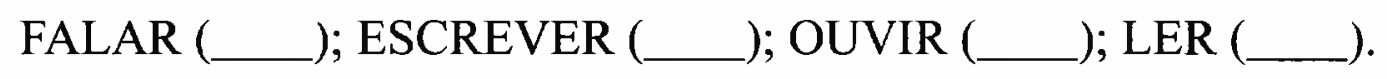

2. Explique brevemente por que você colocou os números nessa ordem. Especifique por que você colocou o número " $\mathrm{X}$ " para a habilidade de "ESCREVER" no ensino-aprendizagem de língua japonesa.

3. Explique brevemente por que, para você, a habilidade de escrita é mais (ou menos) importante (necessário) do que as demais habilidades.

4. No ensino-aprendizagem de língua japonesa (como, por exemplo, na sala de aula), você gosta de "escrever" em língua japonesa, ou não gosta?

6. Neste questionário, a palavra "escrita" se refere, também, à "produção de textos" e ao "ato de digitar" 
Por quê? (Se quiser, pode descrever comparando com outras línguas que você já estudou.)

5. Neste momento, você está fazendo algo para melhorar a habilidade de "escrita" em japonês? Explique brevemente por que você está (ou não) fazendo isso?

\section{Parte 2: Aulas e materiais sobre a "escrita" em japonês}

6. No ensino de língua japonesa, você está recebendo (ou recebeu) alguma orientação/aula sobre a "escrita (produção de textos)" no mesmo idioma?

\section{SIM / NÃO}

7 Se você está recebendo (ou já recebeu), como é (foi) a orientação/aula? Comente brevemente sobre essa orientação/aula, levantando os pontos positivos e os pontos a melhorar.

(Quem nunca recebeu a orientação/aula sobre a "escrita [produção de textos]" em língua japonesa, pule para a questão no. 9.)

8. Que tipo de material(is) está (estão) sendo utilizado(s)? Ou, que tipo de material(is) foi (foram) utilizados? Com relação ao(s) material(is), comente brevemente sobre os pontos positivos e os pontos a melhorar.

9. Que tipo de orientação/aula você desejaria? Por quê?

10. Que tipo de material de "escrita" você desejaria? Por quê?

\section{Parte 3: Necessidade de "escrever" no dia-a-dia}

11. Dentre as quatro habilidades linguísticas (falar, escrever, ouvir, ler), qual habilidade é mais importante/necessária ou interessante para você no diaa-dia? Coloque o número 1 para a habilidade que você considere mais importante/interessante e 4 para habilidade que você considere menos importante/interessante. 
FALAR (_ _ $)$; ESCREVER (__ $)$; OUVIR (__ $)$; LER (_ _ $)$.

12. Explique por que você colocou os números nessa ordem. Especifique por que você colocou o número "X" para a habilidade de "ESCREVER" no dia-a-dia.

13. Em que situação (contexto) você sente fortemente a necessidade de escrever (digitar) em japonês? Escreva todas as situações em que você pensou.

14. Por que, nessas situações (contextos), o ato de comunicação deve ser realizado via "escrita (digitada)" em vez de "falada"?

15. Que tipo de tópicos/assuntos você escreve (digita) em japonês no dia-adia? Escreva todos os tópicos/assuntos em que você pensou.

16. Informe os tópicos/assuntos sobre os quais você ainda não escreveu em japonês, mas gostaria de escrever futuramente. Refira-se a todos os tópicos/assuntos em que você pensou.

Obrigado pela colaboração. 